\title{
Pengelolaan Pemangkasan Tanaman Kopi Arabika (Coffea arabica L.) di Kebun Blawan, Bondowoso, Jawa Timur
}

\author{
Pruning Management of Arabica Coffee (Coffea arabica L.) at Blawan Estate, Bondowoso, East Java
}

\author{
Vinsensia Febrina Sianturi ${ }^{1}$, Ade Wachjar ${ }^{1^{*}}$
}

\author{
${ }^{1}$ Departemen Agronomi dan Hortikultura, Fakultas Pertanian, Institut Pertanian Bogor \\ (Bogor Agricultural University), J1. Meranti, Kampus IPB Darmaga, Bogor 16680, Indonesia \\ Telp.\&Faks.62-251-8629353 e-mail agronipb@indo.net.id \\ *Penulis untuk korespondensi: wachjarade@yahoo.co.id
}

Disetujui 14 November 2016/ Published online 8 Desember 2016

\begin{abstract}
Coffee is one of plantation commodities having economic value sufficiently. Appretinceship activities aimed at learning techniques of cultivated crops and management, coffee plantations studied and analyzed the problem faced by the solutions regarding managements. Pruning trees aimed to stay low, so easy training, branches forming new production. An apprentice activities carried out at the Blawan Estate, Bondowoso, East Java, started February until June 2014. The collection of primary data obtained through observation and direct work practices include plant maintenance activities which cuts off the harvest (observation branches of plants, plant height, number of shoots that grow), while secondary data obtained through the company's management report. Analysis was performed by a quantitative manner, approximately and percentage. Including pruning observed in the category of light pruning. The coffee plant that has a branch condition that equitable and balanced greatly affect the outcome of which must be assessed production. Many branches pruned due to old branches and disease. After pruning, plants produced new shoots.
\end{abstract}

Keywords : coffee, Kebun Blawan, productive branch, prunning

\begin{abstract}
ABSTRAK
Kopi merupakan salah satu komoditas perkebunan yang memiliki nilai ekonomi yang cukup tinggi. Kegiatan magang bertujuan mempelajari teknik budidaya tanaman dan pengelolaan perkebunan kopi, mempelajari dan menganalisis permasalahan yang dihadapi di lapangan mengenai pengelolaan pemangkasan serta solusi mengatasinya. Pemangkasan bertujuan agar pohon tetap rendah sehingga mudah perawatannya, dan membentuk cabang-cabang produksi yang baru. Kegiatan magang dilaksanakan di Kebun Blawan, Bondowoso, Jawa Timur, mulai bulan Februari sampai dengan Juni 2014. Pengumpulan data primer diperoleh melalui pengamatan dan praktik kerja secara langsung meliputi kegiatan pemeliharaan tanaman yaitu pemangkasan lepas panen (pengamatan cabang-cabang tanaman, tinggi tanaman, jumlah tunas yang tumbuh), sedangkan data sekunder diperoleh melalui laporan manajemen perusahaan. Analisis data yang dilakukan secara deskriptif, rata-rata dan persentase. Pemangkasan yang dilakukan termasuk dalam kategori pemangkasan ringan. Tanaman kopi yang memiliki kondisi cabang yang merata dan seimbang sangat mempengaruhi hasil taksasi produksi. Banyak cabang harus dipangkas karena cabang-cabang yang sudah tua dan terserang penyakit. Setelah melakukan pemangkasan, tanaman menghasilkan tunas-tunas baru.
\end{abstract}

Kata kunci : cabang produktif, Kebun Blawan, kopi, pemangkasan 


\section{PENDAHULUAN}

Kopi merupakan salah satu komoditas perkebunan yang memiliki nilai ekonomi yang cukup tinggi di antara tanaman perkebunan lainnya dan berperan penting sebagai sumber devisa negara. Kopi tidak hanya berperan penting sebagai sumber devisa melainkan juga sebagai sumber penghasilan petani kopi di Indonesia (Rahardjo, 2012). Bentuk usaha perkebunan kopi di Indonesia didominasi oleh perkebunan rakyat (PR) dengan porsi $96 \%$ dari total area di Indonesia, $2 \%$ perkebunan besar negara (PBN) dan 2\% perkebunan besar swasta (PBS). Komposisi tersebut menunjukkan peranan petani kopi dalam perekonomian nasional cukup signifikan. Sebaran produksi kopi di Indonesia tidak merata di seluruh daerah/provinsi sehingga hal ini akan menyebabkan wilayah-wilayah basis komoditas kopi di Indonesia hanya terpusat pada beberapa daerah/provinsi saja (Kusmiati dan Windiarti, 2011).

Perkebunan kopi di Indonesia pada tahun 2008 seluas 1295110 ha, produksi kopi sebesar 698016 ton, produktivitas kopi sebesar $729 \mathrm{~kg} / \mathrm{ha}$ dan ekspor kopi sebesar 468000 ton dibandingkan pada tahun 2012 mengalami penurunan menjadi seluas 1233982 hektar, produksi kopi sebesar 657138 ton, produktivitas kopi sebesar $723 \mathrm{~kg} / \mathrm{ha}$, dan ekspor kopi sebesar 448000 ton. Negara tujuan utama ekspor kopi Indonesia adalah ke Eropa yaitu sebesar 26\% dari total ekspor kopi Indonesia (Ditjenbun, 2013).

Salah satu yang mempengaruhi produksi kopi adalah penerapan teknik budidaya tanaman. Teknik budidaya tanaman kopi yang penting dilakukan adalah pembibitan, pembukaan dan persiapan lahan, penanaman penaung, persiapan tanam dan penanaman kopi, pemeliharaan, serta penanganan panen dan pasca panen (Tim Karya Tani Mandiri, 2010). Kegiatan pemeliharaan tanaman kopi meliputi penyulaman, pengendalian gulma, pemupukan, pemangkasan, serta pengendalian hama dan penyakit (Prastowo et al., 2010). Teknik budidaya yang penting dalam peningkatan produksi kopi adalah pemangkasan. Pemangkasan dilakukan untuk mencapai produksi yang optimal. Selain itu pemangkasan sangat berguna untuk memudahkan pemungutan hasil (panen) (Panggabean, 2011). Manfaat dan fungsi pemangkasan umumnya agar pohon tetap rendah sehingga mudah perawatannya, membentuk cabang-cabang produksi yang baru, mempermudah pengendalian hama dan penyakit.

Kegiatan magang bertujuan mempelajari teknik budidaya tanaman dan pengelolaan perkebunan kopi pada keadaan lapangan sesungguhnya, melatih keterampilan dan mendapatkan pengalaman kerja di bidang perkebunan kopi. Selain itu kegiatan magang juga bertujuan mempelajari dan menganalisis permasalahan yang dihadapi di lapangan mengenai pengelolaan pemangkasan serta solusi mengatasinya.

\section{BAHAN DAN METODE}

Kegiatan magang dilaksanakan di Kebun Blawan, Bondowoso, Jawa Timur mulai bulan Februari sampai Juni 2014. Magang dilakukan dengan melakukan pekerjaan secara langsung sesuai dengan kegiatan yang ada di kebun, serta pengumpulan data primer dan data sekunder. Penulis bekerja secara langsung sebagai karyawan dengan jenis kegiatan yang sedang dilaksanakan di kebun. Kegiatan magang dilaksanakan dalam tiga tahap yaitu tahap pertama sebagai karyawan harian lepas (KHL) selama satu bulan, dengan melakukan semua kegiatan lapangan yang terdiri atas pembibitan, persiapan tanam dan penanaman, pemeliharaan tanaman (pemupukan, pengendalian gulma, pembuatan rorak, pemangkasan tanaman kopi, serta pengendalian hama dan penyakit), pemangkasan tanaman pelindung, pemanenan, serta pasca panen.

Tahap kedua sebagai pendamping mandor lapangan, mandor besar. Sebagai pendamping mandor lapangan, penulis melaksanakan tugas utama membantu mandor lapangan dalam membuat perencanaan dan pengawasan kegiatan pemeliharaan tanaman dan pemanenan. Sebagai pendamping mandor besar, penulis bertugas membantu mandor besar membuat perencanaan dan pengawasan mandor lapangan serta penilaian kegiatan yang dilakukan mandor lapangan, menghitung jumlah tenaga kerja yang hadir, membantu mengawasi dan mengorganisir kerja karyawan harian di lapangan, membuat analisis pada setiap kegiatan perkebunan di lapangan, membantu membuat laporan harian serta mengisi jurnal kegiatan harian. Tahap ketiga sebagai pendamping asisten tanaman, penulis bertugas membantu asisten tanaman melakukan pengawasan kinerja mandor besar, pengelolaan kebun di tingkat afdeling dan membuat perencanaan kegiatan budidaya.

Pengamatan difokuskan pada kegiatan pemangkasan dengan beberapa parameter yang mendukung pertumbuhan dan produksi tanaman. Populasi tanaman kopi Arabika di Kebun Blawan rata-rata 1949 pohon/ha, untuk pengamatan ditentukan jumlah pohon contoh sebanyak 10 tanaman per blok. Pengamatan dilakukan sebanyak tiga ulangan. Pengamatan dilakukan 
dengan pengumpulan data di lapangan khusus aspek pemangkasan. Pengamatan dilakukan lima blok, masing-masing blok memiliki perbedaan tahun tanam. Cara pengambilan sampel yaitu dipilih secara acak. Pengamatan dibagi atas tiga tahap yaitu sebelum pemangkasan,saat pemangkasan dan sesudah pemangkasan.

Pengamatan sebelum pemangkasan:

1. Tinggi tanaman, diukur dari permukaan tanah sampai titik tumbuh tertinggi.

2. Jenis cabang kopi, cabang-cabang yang ada di setiap tanaman kopi sebelum pemangkasan diklasifikasikan berdasarkan jumlah cabang belum berbuah $\left(\mathrm{B}_{0}\right)$, jumlah cabang berbuah satu kali $\left(B_{1}\right)$, jumlah cabang berbuah dua kali $\left(B_{2}\right)$ dengan jumlah cabang berbuah tiga kali $\left(\mathrm{B}_{3}\right)$.

3. Taksasi produksi

Menurut Tampubolon (2002), perhitungan taksasi hasil dilakukan dengan menggunakan rumus yang baku, yaitu

$$
P=\left\{\frac{(\Sigma(A \times B)) x C}{e}\right\}
$$

Keterangan:

$\mathrm{P}=$ hasil taksasi produksi

$A=$ rata-rata jumlah buah per pohon

$\mathrm{B}=$ persentase keberhasilan,

$\mathrm{C}=$ populasi tanaman

$\mathrm{e}=$ jumlah biji kopi untuk $1 \mathrm{~kg}$ kopi.

Pengamatan saat pemangkasan meliputi pengamatan pada peubah jumlah cabang produktif dan cabang tidak produktif. Pengamatan setelah pemangkasan meliputi pengamatan pada peubah jumlah tunas yang tumbuh. Pengamatan dilakukan 1 bulan sekali mulai 2 minggu setelah pemangkasan (MSP) hingga 2 bulan berikutnya.

Pengumpulan data primer dan informasi diperoleh melalui pengamatan dan praktik kerja secara langsung meliputi kegiatan pemeliharaan tanaman yaitu pemangkasan lepas panen (pengamatan cabang-cabang tanaman, tinggi tanaman, taksasi produksi, jumlah tunas yang tumbuh). Selain itu, data primer diperoleh dari hasil wawancara dan diskusi dengan staf serta karyawan kebun. Data sekunder diperoleh dari laporan manajemen kebun berupa laporan bulanan, triwulan, semesteran dan tahunan serta dari pustaka di Kebun Blawan PT Perkebunan Nusantara XII, Bondowoso yang mencakup letak wilayah administratif, keadaan tanah dan iklim, luas areal konsesi dan tata guna lahan, keadaan pertanaman dan produksi, struktur organisasi dan ketenagakerjaan, serta peta kebun. Khusus untuk aspek pemangkasan data sekunder yaitu kategori pangkasan untuk standar perusahaan.
Data primer yang diperoleh dianalisis dengan menggunakan analisis statistika deskriptif yaitu analisis yang dilakukan secara kuantitatif yaitu rata-rata dan persentase. Hasil olahan data tersebut disajikan dalam bentuk tabel, kemudian dibahas secara deskriptif dengan membandingkan data terhadap standar yang ditetapkan oleh kebun maupun studi pustaka (literatur).

\section{HASIL DAN PEMBAHASAN}

\section{Kondisi Umum}

Kebun Blawan sejak awal merupakan Perkebunan Kopi Arabika yang penanaman pertamanya dilaksanakan pada tahun 1894 sebagai milik warga Belanda. Kebun Blawan berada di kawasan Gunung Ijen yang lokasinya berdekatan dengan kebun Kopi Arabika milik PTPN XII lainnya, yaitu Kebun Kalisat Jampit, Kebun Pancur Angkrek, dan Kebun Kayumas. Kebun Blawan terletak pada ketinggian 900-1 500 meter di atas permukaan laut dan mempunyai topografi lahan bergelombang sampai dengan berbukit. Berdasarkan curah hujan lima tahun terakhir (2009-2013) keadaan iklim di Kebun Blawan termasuk ke dalam tipe iklim D sampai E menurut Schmidth-Ferguson, dengan curah hujan rata-rata tahunan $1504 \mathrm{~mm} /$ tahun dan jumlah hari hujan 114 hari, serta 5.6 bulan basah dan 5.2 bulan kering. Kebun Blawan memiliki luas areal konsensi 4751 ha. Tanaman kopi yang diusahakan di Kebun Blawan adalah jenis Arabika dengan tahun tanam yang bervariasi (mulai dari tahun 1974 - 2010).

Kebun Blawan dipimpin oleh seorang manajer dengan dibantu oleh wakil manajer, asisten akuntansi (asaku), asisten teknik dan pengolahan (astekpol) dan sembilan asisten tanaman. Setiap asisten dibantu oleh mandor besar, mandor bedengan, mandor pengajiran, mandor pembuatan lubang tanam, mandor pengendalian gulma manual, mandor pemeliharaan naungan sementara, mandor pemupukan, mandor pangkas pemeliharaan, mandor pangkas bentuk.

\section{Aspek Teknis}

Kegiatan teknis yang dilakukan di kebun selama magang, yaitu sebagai karyawan harian lepas (KHL). Pekerjaan di lapangan diawali dengan mengikuti apel pagi setiap hari kerja pukul 06.00 WIB. Pada saat apel pagi tersebut dilakukan absensi kehadiran dan pembagian hanca panen untuk setiap pemanen. Semua kegiatan dimulai pada pukul 07.00-12.00 WIB dan dilanjutkan 
kembali pada pukul 14.00-16.00 WIB. Sedangkan untuk hari Jumat kegiatan dilakukan pada pukul 07.00-11.30 dan dilanjutkan kembali pukul 13.3016.00. Sistem pengaturan jam kerja untuk karyawan pabrik (pengolahan) dibagi dalam 3 shift, dengan masing-masing shift 7 jam kerja.

Pemeliharaan Pembibitan. Kegiatan pembibitan di Kebun Blawan bertujuan untuk menyediakan bahan sulaman. Pembibitan dilakukan melalui sambungan hipokotil kopi dan batang bawah yang akan disambung dengan entres. Bahan tanam untuk batang bawah berasal dari benih kopi Excelsa (Coffea excelsa A. Chev), sedangkan batang atas berasal dari kopi Arabika varietas USDA 762 dan komposit. Keuntungan penggunaan batang bawah dari kopi Excelsa yaitu lebih tahan terhadap kekeringan dan nematoda.

Kegiatan di pembibitan terdiri atas pembuatan bedengan persemaian, pendederan benih, pemeliharaan kecambah kopi, pembuatan media tanam di polybag, penanaman bibit di polybag dan pemeliharaan di pembibitan. Sebelum dilakukan penanaman bibit di polybag, terlebih dahulu dilakukan pengambilan pupuk kandang dan tanah, pengisian dan penataan polybag, panyambungan hipokotil (serdadu), penyambungan entres. Selanjutnya, untuk pemeliharaan di pembibitan meliputi pengendalian gulma di dalam polybag, pengendalian gulma di areal bedengan dan penyiraman, dan pengendalian hama dan penyakit.

Kegiatan yang dilakukan pada sambung hipokotil atau sambung serdadu adalah menyambung bibit kopi yang masih berumur 3040 hari dengan batang bawah jenis kopi Robusta dan batang atas kopi Arabika. Kegiatan yang dilakukan pada sambung entres adalah pemotongan entres satu ruas $6-8 \mathrm{~cm}$ dengan sepasang daun di batangnya, kemudian pangkal stek dibuat runcing (sudut $45^{\circ}$ ). Pengendalian gulma di pembibitan dilaksanakan dengan cara manual yaitu dengan cara membabad gulma di sekitar bibit kopi yang ada di dalam polybag dan yang ada di sekitar bedengan dengan menggunakan cangkul dan sabit. Penyiraman pembibitan dilakukan setiap hari dengan menggunakan selang air. Sumber air untuk penyiraman pembibitan berasal dari sungai yang berada di dekat areal bedengan.

Pemeliharaan tanaman. Kegiatan yang dilaksanakan terdiri atas pengendalian gulma, pembuatan rorak, pemupukan, pemangkasan tanaman kopi, dan pengendalian hama penyakit.
Berikut adalah penjelasan kegiatan pemeliharaan yang dilaksanakan penulis di lapangan.

Pengendalian gulma dilaksanakan sebelum pemupukan, sebelum panen, dan bila populasi gulma telah mengganggu tanaman kopi dan kegiatan budidaya lainnya. Pengendalian gulma sebelum pemupukan bertujuan untuk menghindari persaingan penyerapan hara antara tanaman kopi dengan gulma, sedangkan pengendalian gulma menjelang panen bertujuan untuk memudahkan dalam pemanenan dan mengurangi jumlah kehilangan buah yang jatuh ke tanah.

Pengendalian gulma dilaksanakan dengan dua cara yaitu secara manual dan kimia disesuaikan dengan kebutuhan kebun. Pengendalian gulma secara manual dilaksanakan dengan cara membabad gulma di sekitar tanaman kopi seluas proyeksi tajuk tanaman dengan menggunakan sabit dan cangkul. Pengendalian gulma secara kimiawi dilakukan dengan menggunakan herbisida. Herbisida yang digunakan ialah herbisida sistemik dengan bahan aktif yaitu Gliphosate, Sulphosate, dengan sasaran selektif gulma berdaun sempit, 2.4 Damin dengan sasaran utama gulma berdaun lebar.

Pembuatan rorak dilaksanakan menjelang musim hujan dengan tujuan untuk konservasi air, mencegah run off, menahan humus, dan tempat penampungan bahan organik. Rorak yang dibuat berukuran panjang $75-100 \mathrm{~cm}$, lebar $30-40 \mathrm{~cm}$, dalam 40-60 $\mathrm{cm}$ dan jarak dari tanaman kopi antara $60-100 \mathrm{~cm}$ bergantung pada besar kecilnya tanaman. Pembuatan rorak dilakukan dengan berpindah-pindah tempat, di antara dua tanaman kopi secara bergiliran. Alat yang digunakan adalah cangkul dan sabit. Pembuatan rorak dimulai dari pengendalian gulma di sekitar tanaman kopi dengan cara dibabad, kemudian gulma hasil penyiangan tersebut dikumpulkan di salah satu sisi yang bersebrangan dengan rorak yang akan dibuat. Dengan demikian posisi rorak lebih rendah daripada tanah di sekitarnya, sehingga jika ada kelebihan air, air dapat mengalir ke dalam rorak.

Pemupukan. Pemupukan dilakukan untuk mempertahankan dan memperbaiki kesuburan tanah, sehingga produktivitas tanah dapat meningkat dan diperoleh hasil tanaman yang optimal. Pemupukan tanaman kopi di Kebun Blawan dilakukan dua kali dalam setahun yakni semester satu pada bulan Maret-April dan semester 2 pada bulan Oktober-November. Pekerjaan pemupukan umumnya dilakukan oleh tenaga kerja wanita dengan organisasi tugasnya yaitu pengangkutan, pengeceran, penabur dan penutup lubang pupuk. Pengangkutan dimulai dari 
tempat pencampuran pupuk, selanjutnya diecer ke masing-masing ember tenaga pemupuk. Penaburan pupuk dilakukan dengan menggunakan wadah yang sudah ditentukan takaran dosis per pohonnya. Kemudian melakukan penutupan pada lubang yang sudah ditaburi pupuk dengan alat berupa cangkul.

Masalah yang biasanya timbul pada saat pemupukan, yaitu pupuk tidak diberikan secara tepat pada alur pupuk yang telah dibuat. Penutupan pupuk dengan tanah yang kurang sempurna, sehingga dapat mengurangi efisiensi serapan pupuk oleh tanaman kopi akibat penguapan atau hilang tercuci air. Proses pengangkutan pupuk oleh tenaga pemupuk yang kurang sempurna sehingga pupuk jatuh di jalan. Hal tersebut terjadi karena proses pengawasan oleh mandor terhadap tenaga pemupuk kurang intensif. Selain itu, topografi lahan yang curam dan berbukit juga menyulitkan tenaga pemupuk untuk mengangkut pupuk tersebut.

Jenis pupuk anorganik yang digunakan yaitu Urea, SP-36, KCl, Kieserit Jenis dan dosis pupuk tersebut dibedakan berdasarkan umur tanaman kopi. Anjuran dosis yang digunakan di Kebun Blawan dapat dilihat pada Tabel 1.

Tabel 1. Pupuk anjuran tanaman kopi di Kebun Blawan

\begin{tabular}{crrrr}
\hline Umur & \multicolumn{4}{c}{ Dosis (g/ pohon) } \\
\cline { 2 - 5 } (Tahun) & Urea & TSP & KCl & Kies. \\
\hline 1 & 20 & 20 & 20 & 10 \\
2 & 40 & 40 & 40 & 20 \\
3 & 80 & 80 & 80 & 40 \\
4 & 160 & 160 & 160 & 80 \\
5 & 200 & 200 & 200 & 100 \\
6 & 400 & 400 & 400 & 200 \\
\hline
\end{tabular}

Keterangan : Dosis yang tercantum merupakan dosis anjuran per tahun

Pemangkasan tanaman kopi. Tujuan Pemangkasan adalah mempertahankan ketinggian tanaman dengan tinggi $160 \mathrm{~cm}$ untuk memudahkan perawatan atau pemeliharaan dan panen. Pemangkasan batang tunggal (single stem) terdiri dari pangkas bentuk, pemeliharaan, dan peremajaan. Pemangkasan bentuk yaitu perlakuan kliping terutama untuk tanaman yang sulit menumbuhkan cabang reproduktif. Pemangkasan pemeliharaan atau pemangkasan produksi terdiri atas pangkas lepas panen (PLP), pangkas seleksi (wiwil selektif) dan wiwil kasar. Cabang-cabang yang terdapat di tanaman kopi adalah cabang belum berbuah (B0), cabang yang telah berbuah satu kali (B1), cabang yang yang telah berbuah dua kali (B2), dan cabang yang telah berbuah tiga kali (B3). Cabang-cabang yang termasuk cabang produktif adalah cabang B1, B2, dan B3.
Pemangkasan seleksi bertujuan mempersiapkan cabang pemikul buah untuk persediaan tahun yang akan datang. Pada prinsipnya cabang-cabang yang berlebihan harus dipangkas agar cahaya matahari dapat masuk ke dalam tajuk dan sirkulasi udara berlangsung baik, sehingga proses pertumbuhan menjadi baik. Pemangkasan seleksi dilaksanakan dua kali dalam setahun. Pemangkasan seleksi mulai dilakukan 23 bulan setelah PLP (Desember-Januari) dengan memilih cabang-cabang yang akan dipelihara pada musim pembungaan yang akan datang. Pemangkasan halus dilakukan untuk mengurangi kelembaban yang terjadi pada tanaman, sehingga dapat mengurangi gugur buah. Pemangkasan halus di Kebun Blawan dilakukan bersamaan dengan pemangkasan seleksi kedua. Pemangkasan halus dilakukan dengan membuang tunas air, rawisan dan pengupiran daun yang sudah tua yang tumbuh dekat buah. Alat yang digunakan gergaji dan gunting pangkas.

Pengamatan yang dilakukan adalah pemangkasan lepas panen yang kedua. Pengamatan ini dilakukan untuk mengamati cabang-cabang tanaman. Kriteria pemangkasan pemeliharaan terdiri atas pangkasan berat, pangkasan sedang dan pangkasan ringan (Anggara dan Marini, 2011). Pemangkasan yang dilakukan termasuk dalam kategori pemangkasan ringan karena pemangkasan berat sudah dilakukan setelah lepas panen pada bulan OktoberNovember. Kategori pemangkasan ringan yaitu apabila kondisi pohon sebelum dipangkas memiliki cabang-cabang B0, B1, B2 dalam proporsi seimbang sesuai standar perusahaan yaitu masing-masing cabang 33\% dari total cabang tanaman dan kondisi cabang-cabang B2 tetap dipertahankan. Untuk mempertahankan kondisi cabang tersebut, maka pemangkasan yang dilakukan hanya pangkas wiwil kasar dan pangkas wiwil selektif (PTPN XII, 2012). Pemangkasan dilakukan untuk mengetahui jenis-jenis cabang yang terdapat di tanaman.

Berdasarkan hasil pengamatan pada (Tabel 2). Cabang-cabang B0 yang paling banyak terdapat di blok Arabusta, cabang-cabang B1 paling banyak terdapat di Blok Kalirejo 1989, cabang-cabang B2 paling banyak terdapat di Blok Kayu Manis 1999 sedangkan cabang-cabang B3 paling banyak terdapat di Blok C. Tanaman kopi di Blok Kalirejo 2010 termasuk kategori proporsi seimbang karena kondisi persentase cabangcabang B0, B1, dan B2 yang terdapat di pohon perbandingan tidak berbeda jauh. Tanaman kopi di Blok Kalirejo 2010 memiliki cabang-cabang yang kondisinya merata dan seimbang, sehingga sangat mempengaruhi hasil taksasi produksi. Hasil 
taksasi produksi tanaman kopi di Blok Kalirejo 2010 sangat besar, dan kondisi tanaman Kopi di Blok Kalirejo sangat baik dan terpelihara.

Cabang-cabang tanaman kopi di Blok C 1986 termasuk proporsi tidak seimbang karena cabang-cabang B1 sedikit tetapi terlalu banyak di cabang-cabang B3. Kondisi cabang-cabang B3 memiliki sedikit dompolan buah, dan pada tahun selanjutnya cabang-cabang B3 akan semakin rusak karena cabang-cabangnya semakin tua. Tanaman kopi di Blok C memiliki banyak cabang, tetapi hasil taksasi produksi yang diperoleh tidak maksimal, karena persentase masing-masing cabang B0, B1, B2 tidak merata dan B3 sangat banyak. Pengamatan persentase jenis cabang dihubungkan dengan taksasi produksi disajikan pada Tabel 2.

Tabel 2. Hubungan antara persentase jenis cabang dengan hasil taksasi produksi tanaman kopi Arabika di Kebun Blawan

\begin{tabular}{lcccccccccc}
\hline \multirow{2}{*}{$\begin{array}{c}\text { Blok } \\
\text { kebun }\end{array}$} & \multirow{2}{*}{$\begin{array}{c}\text { Tahun } \\
\text { tanam }\end{array}$} & \multirow{2}{*}{$\begin{array}{c}\text { Jumlah populasi } \\
\text { (pohon) }\end{array}$} & \multirow{2}{*}{$\begin{array}{c}\text { Jumlah contoh } \\
\text { (pohon) }\end{array}$} & B0 & B1 & B2 & B3 & $\begin{array}{c}\text { Total cabang } \\
\text { pohon contoh } \\
\text { (cabang) }\end{array}$ & $\begin{array}{c}\text { Taksasi produksi } \\
\text { pohon contoh } \\
\text { (kg) }\end{array}$ \\
\hline Kalirejo & 2010 & 16876 & 10 & 27.3 & 26.4 & 22.6 & 23.7 & & 587 & 3.65 \\
Kalirejo & 1989 & 14839 & 10 & 19.6 & 30.3 & 23.3 & 26.8 & 373 & 1.76 \\
C & 1986 & 15020 & 10 & 18.1 & 13.1 & 21.3 & 47.5 & 724 & 2.83 \\
Arabusta & 1982 & 10019 & 10 & 28.3 & 21.6 & 20.6 & 29.5 & 533 & 1.87 \\
Kayu Manis & 1999 & 3411 & 10 & 14.4 & 21.1 & 33.5 & 31.0 & 826 & 6.45 \\
\hline
\end{tabular}

keterangan : $\quad$ B0 : Cabang belum berbuah, B1 : Cabang yang telah berbuah satu kali, B2 : Cabang yang telah berbuah dua kali, B3 : Cabang yang telah berbuah tiga kali

Hasil pengamatan cabang-cabang produktif dan cabang yang tidak produktif dicantumkan pada Tabel 3. Berdasarkan hasil pengamatan pada (Tabel 3). Cabang-cabang yang produktif paling banyak terdapat di Blok Kayu Manis 1999, sedangkan cabang-cabang tanaman kopi di Blok C dan Blok Arabusta dikategorikan sedang. Cabang-cabang produktif tanaman kopi di Blok Kalirejo 2010 dan Blok Kalirejo 1989 dikategorikan sedikit. Rata-rata jumlah cabang yang tidak produktif paling banyak adalah di Blok $\mathrm{C}$, dibandingkan rata-rata jumlah cabang di Blok Kalirejo 2010 dikategorikan sedikit. Tanaman kopi di Blok $\mathrm{C}$ banyak cabang yang harus dipangkas disebabkan cabang-cabang tua, dan terserang penyakit. Cabang yang produktif (Tabel 3) terlihat sangat bervariasi tidak bergantung pada tahun tanam.

Tabel 3. Rata-rata jumlah cabang-cabang produktif dan cabang-cabang tidak produktif tanaman kopi Arabika di Kebun Blawan

\begin{tabular}{lccccc}
\hline Blok kebun & $\begin{array}{c}\text { Tahun } \\
\text { tanam }\end{array}$ & $\begin{array}{c}\text { Jumlah populasi } \\
\text { (pohon) }\end{array}$ & $\begin{array}{c}\text { Jumlah contoh } \\
\text { (pohon) }\end{array}$ & $\begin{array}{c}\text { Rata-rata cabang } \\
\text { produktif } \\
\text { (cabang) }\end{array}$ & $\begin{array}{c}\text { Rata-rata cabang } \\
\text { tidak produktif } \\
\text { (cabang) }\end{array}$ \\
\hline Kalirejo & 2010 & 16876 & 10 & 42.7 & 5.6 \\
Kalirejo & 1989 & 14839 & 10 & 30.0 & 8.7 \\
Blok C & 1986 & 15020 & 10 & 59.3 & 8.8 \\
Arabusta & 1982 & 10019 & 10 & 53.3 & 8.6 \\
Kayu Manis & 1999 & 3411 & 10 & 82.6 & 7.4 \\
\hline
\end{tabular}

Tinggi tanaman kopi untuk tanaman menghasilkan menurut standar perusahaan adalah tidak melebihi $160 \mathrm{~cm}$ untuk mempermudah pemeliharaan dan saat pemanenan. Pengamatan tinggi tanaman kopi di Kebun Pengamatan tinggi tanaman (Tabel 4) untuk mengetahui tingkat pertumbuhan tanaman, produktivitas tanaman dan meratakan standar optimal tinggi tanaman di kebun. Pengamatan rata-rata tinggi tanaman tertinggi adalah tanaman kopi di Blok Kalirejo 1989. Kondisi tanaman di Blok Kalirejo 1989 pada umumnya tinggi tanaman lebih dari $160 \mathrm{~cm}$, tanaman juga subur, sedikit yang terkena hama dan penyakit. Tinggi tanaman yang lebih dari 160 $\mathrm{cm}$ memiliki banyak cabang-cabang B3, dan B4 yaitu cabang-cabang tua yang mempunyai jumlah dompolan sedikit, sehingga hasil taksasi produksi yang di dapat dari blok tersebut kurang maksimal.

Tanaman kopi untuk hasil yang lebih optimal tidak melebihi $160 \mathrm{~cm}$, karena tanaman tersebut kondisi cabang-cabangnya produktif sedikit, banyak cabang-cabang tua, dan saat panen pemetik tidak sulit memetik kopi. Tanaman yang tahun tanam lebih tua seperti di Blok Kalirejo 1989, Blok C 1986, dan Blok Arabusta 1982 memiliki rata-rata tinggi tanaman lebih tinggi 
dibandingkan tanaman kopi di Blok Kayu Manis 1999 dan di Blok Kalirejo 2010 yang termasuk kategori tanaman kopi muda. Tanaman Kopi di Blok Kayu Manis 1999 memiliki total cabang yang paling banyak, sedangkan di Blok Kalirejo 1989 memiliki total cabang tanaman kopi paling sedikit. Kondisi cabang tanaman kopi di Blok Kayu Manis terpelihara, tinggi tanamannya sesuai dengan standar tinggi tanaman kopi. Cabangcabang tanaman kopi di Blok Kayu Manis lebih banyak produktif, karena cabang-cabang yang tidak produktif sudah dipangkas. Tanaman kopi akan lebih produktif dan tumbuh banyak cabang baru jika cabang-cabang yang tidak produktif segera dipangkas.

Tabel 4. Rata-rata tinggi tanaman dengan jumlah cabang tanaman kopi Arabika di Kebun Blawan

\begin{tabular}{lccccccc}
\hline \multirow{2}{*}{ Blok kebun } & \multirow{2}{*}{$\begin{array}{c}\text { Tahun } \\
\text { tanam }\end{array}$} & \multirow{2}{*}{$\begin{array}{c}\text { Jumlah populasi } \\
\text { (pohon) }\end{array}$} & $\begin{array}{c}\text { Jumlah contoh } \\
\text { (pohon) }\end{array}$ & \multicolumn{2}{c}{$\begin{array}{c}\text { Rata-rata tinggi tanaman } \\
\text { (cm) }\end{array}$} & \multicolumn{2}{c}{$\begin{array}{c}\text { Jarak antar cabang di } \\
\text { pohon contoh }(\mathrm{cm})\end{array}$} \\
\hline Kalirejo & 2010 & 16876 & 10 & 116.2 & 122.1 & 124.2 & 4.6 \\
Kalirejo & 1989 & 14839 & 10 & 151.9 & 154.4 & 156.0 & 7.5 \\
Blok C & 1986 & 15020 & 10 & 142.3 & 145.5 & 148.3 & 4.8 \\
Arabusta & 1982 & 10019 & 10 & 134.0 & 135.2 & 136.7 & 5.2 \\
Kayu Manis & 1999 & 3411 & 10 & 125.6 & 134.2 & 136.0 & 4.2 \\
\hline
\end{tabular}

Setelah melakukan pemangkasan, tanaman menghasilkan tunas-tunas baru dicantumkan pada Tabel 5. Cabang-cabang yang tidak produktif segera dipangkas untuk menghasilkan tunas-tunas baru sehingga cabangcabang semakin banyak dan produktif.

Berdasarkan hasil pengamatan (Tabel 5). Rata-rata jumlah tunas yang tumbuh paling banyak di Blok Arabusta 1989 dan Blok Kalirejo 1989, tunas yang tumbuh di Blok Kayu Manis 1999 dikategorikan sedang. sedangkan tunas yang tumbuh di Blok Kalirejo 2010 dan Blok Arabusta 1998 dikategorikan sedikit. Cabang-cabang tua yang dipangkas menghasilkan tunas-tunas baru. Tunas yang tumbuh bervariasi antar blok tetapi tidak berhubungan dengan umur tanaman. Perbedaan ini diduga karena faktor kesuburan tanah dan iklim mikro masing-masing blok pertanaman. Cabang-cabang yang dipangkas saat ini sangat mempengaruhi jumlah cabang dan produksi untuk tahun selanjutnya.

Tabel 5. Jumlah tunas yang tumbuh setelah pemangkasan cabang tanaman kopi Arabika di Kebun Blawan

\begin{tabular}{llccc}
\hline \multicolumn{1}{c}{ Blok kebun } & $\begin{array}{c}\text { Tahun } \\
\text { tanam }\end{array}$ & $\begin{array}{c}\text { Jumlah populasi } \\
\text { (pohon) }\end{array}$ & $\begin{array}{c}\text { Jumlah contoh } \\
\text { (pohon) }\end{array}$ & $\begin{array}{c}\text { Tunas yang tumbuh } \\
\text { (tunas) }\end{array}$ \\
\hline Kalirejo & 2010 & 16876 & 10 & 3.8 \\
Kalirejo & 1989 & 14839 & 10 & 8.6 \\
Blok C & 1986 & 15020 & 10 & 5.2 \\
Arabusta & 1982 & 10019 & 10 & 10.6 \\
Kayu Manis & 1999 & 3411 & 10 & 6.5 \\
\hline
\end{tabular}

Pengendalian hama dan penyakit. Hama dan penyakit yang dominan terdapat di Kebun Blawan adalah hama bubuk buah kopi (Hypotenemus hampei) dan nematoda. Ketersediaan buah di pertanaman yang terus menerus memungkinkan perkembangan serangan hama bubuk buah kopi secara berkesinambungan dari generasi ke generasi. Petik bubuk dilakukan mulai bulan Maret-April kurang lebih 1 bulan menjelang panen, ditujukan untuk mengurangi sumber infeksi bubuk buah dipertanaman.

Gejala tanaman yang terserang nematoda yaitu tanaman kerdil, pertumbuhan terhambat, ukuran daun dan cabang primer kecil, daun tua menjadi kuning secara perlahan-lahan, dan akhirnya mati. Kebun Blawan mengendalikan nematoda dengan menggunakan trichoderma saat dilakukan penanaman. Penggunaan trichoderma sangat berpengaruh untuk mengurangi nematoda pada tanaman kopi.

Pemangkasan tanaman pelindung. Pemangkasan tanaman pelindung tetap dilakukan agar tanaman kopi mendapat sinar matahari yang cukup untuk merangsang pembungaan, memperlancar sirkulasi udara dalam kebun serta mengurangi kelembaban udara pada waktu musim hujan. Tanaman pelindung tetap yang ada di Kebun Blawan yaitu tanaman lamtoro klon L2, dan ramayana (Cassia spektabilis). Tinggi tanaman pelindung yang baik yaitu dua kali tinggi tanaman kopi $(3-3.5 \mathrm{~m})$.

Pemangkasan tanaman pelindung tetap terdiri atas pemangkasan bentuk dan pemangkasan pengaturan. Pemangkasan bentuk dilakukan dengan cara membuang cabang-cabang 
yang tumbuh sebelum tanaman mencapai ketinggian $1.5 \mathrm{~m}$, sehingga pertumbuhan tanaman lurus dan mengarah ke atas. Pemangkasan pengaturan terdiri atas pemenggalan (tokok) dan rempes. Tokok dilakukan pada awal musim hujan (bulan November-Desember) dengan mencapai $50 \%$ dari jumlah tanaman pelindung tetap setinggi $1.5 \mathrm{~m}$ di atas tajuk tanaman kopi dan dilakukan bergantian setiap tahun menurut larikan atau silangan. Selanjutnya, dua sampai tiga bulan setelah di tokok dilakukan seleksi cabang dan dipilih tiga cabang tanaman yang arahnya menyebar. Rawisan dilakukan dengan tujuan membuang cabang-cabang yang tumbuh selama musim hujan. Alat yang digunakan untuk rempes adalah sabit dan gergaji.

Pemanenan. Pemanenan merupakan akhir dari kegiatan budidaya di kebun sebelum buah kopi diangkut ke pabrik. Tahapan pemanenan di Kebun Blawan meliputi taksasi buah, pertemuan teknis panen, selamatan panen, persiapan panen dan pembuatan jadwal panen. Taksasi buah di Kebun Blawan dilaksanakan dua bulan sebelum panen. Pada tahun 2014, taksasi buah di Kebun Blawan dilakukan pada bulan Februari.

Taksasi produksi. Sebelum melakukan pemanenan terlebih dahulu dilakukan taksasi untuk memperkirakan produksi buah kopi yang akan dicapai serta memudahkan dalam penentuan biaya dan jumlah tenaga pemetik yang diperlukan selama pemanenan dilakukan. Taksasi dilakukan pada buah kopi yang memiliki ukuran maksimum. Untuk bisa disebut biji ukuran besar harus memenuhi persyaratan tidak lolos pada ayakan ukuran $5.6 \mathrm{~mm}$ x $5.6 \mathrm{~mm}$. Taksasi dilakukan dua bulan sebelum dilaksanakan pemanenan. Metode yang dilakukan adalah mengelompokkan areal berdasarkan tahun tanam, yaitu setiap blok yang memiliki tahun tanam yang sama, kemudian diambil beberapa pohon untuk dijadikan sampel.

Pelaksanaan taksasi diawali dengan menentukan tanaman sampel berdasarkan sistem acak teratur (systematic random sampling). Pada sistem tersebut ditentukan sampel tanaman dengan cara membuat garis silang secara acak sesuai kebutuhan pengamatan, dengan kelipatan 10-20 pohon pada tiap blok per tahun tanaman. Jumlah pohon sampel ditentukan $0.5 \%$ dari populasi tanaman per blok. Penghitungan buah dilakukan pada buah yang masih hijau dan diperkirakan dapat dipanen pada dua bulan kedepan.

Persiapan panen. Persiapan panen meliputi persiapan lapangan, penyediaan alat panen, persiapan tenaga pemetik dan pembuatan jadwal panen. Persiapan lapangan yaitu membersihkan kebun pada saat sebelum dan selama panen, terutama di sekitar pohon agar buah yang tercecer dapat dikumpulkan. Setiap karyawan petik membawa kocok (keranjang plastik) dan tekotek (tas dari bahan karung), sapu, tangga dan tanda pengenal, timbangan, lampu petromax/emergency, bendera mandor dengan warna yang berbeda, bendera. Tempat pengumpulan hasil (TPH), bendera lokasi petik, kentongan. Persiapan tenaga pemetik dilakukan dengan menghitung kebutuhan dan perekrutan tenaga pemetik agar saat panen tidak terjadi kekurangan tenaga pemetik. Pembuatan jadwal panen dilakukan sesuai dengan rotasi panen yang telah ditetapkan kebun berdasarkan kecepatan kematangan buah kopi antar blok. Selain itu, pembuatan jadwal panen juga harus mempertimbangkan kemampuan sarana angkutan dan rencana pengolahan.

Pengolahan Hasil. Pengolahan buah kopi terbagi atas dua cara yaitu pengolahan basah (wet process) dan pengolahan kering (dry process).

Pengolahan basah. Pengolahan basah dilakukan hanya pada buah kopi yang memiliki buah dengan kualitas superior. Pengolahan ini menggunakan dua jenis fermentasi yaitu fermentasi basah dan fermentasi kering. Tahapan pengolahan basah yaitu Tahapan pengolahan basah yaitu buah kopi merah dimasukkan ke dalam bak syphon berisi air, dialirkan ke raung pulper untuk dikupas kulit buah, lalu dialirkan ke bak pencucian, kemudian biji dikeringkan dengan mason dryer, lalu dimasukkan ke mesin huller untuk memisahkan kulit ari dan kulit tanduk, kemudian biji disortasi.

Pengolahan kering. Pengolahan kering digunakan untuk mengolah buah kopi hijau, rambangan, hitam dan terserang hama/penyakit (buah inferior). Tahapan pengolahan kering yaitu diawali dengan penjemuran di bawah sinar matahari selama 10 hari, dimasukkan ke mesin viss dryer, lalu ke mesin huller, kemudian biji disortasi.

\section{Aspek Manajerial}

Tenaga kerja di Kebun Blawan dibedakan menjadi tenaga staf dan non staf. Tenaga staf di Kebun Blawan meliputi manajer, wakil manajer, asisten tanaman, asisten teknik dan pengolahan, asisten akuntansi, mandor besar dan beberapa mandor lapang yang sudah memiliki golongan. Tenaga non staf di Kebun Blawan meliputi mandor non golongan, beberapa karyawan kantor induk, dan sopir. 
Aspek manajerial yang dilakukan penulis di perkebunan kopi, dimulai dari pendamping mandor, pendamping mandor kepala dan pendamping asisten tanaman. Organisasi tersebut menerapkan organisasi yang sederhana dengan struktur organisasi yang jelas sehingga tidak menjadi lempar kewajiban dan tanggung jawab.

Pendamping asisten tanaman. Asisten tanaman bertugas memimpin dan mengelola kebun serta bertanggungjawab terhadap produksi yang terdapat di afdeling yang dipimpinnya. Dalam melaksanakan tugasnya, asisten tanaman dibantu oleh mandor besar dan mandor. Sebagai pendamping asisten tanaman, penulis menerima instruksi dan bimbingan dari asisten tanaman dan manajer. Selama kegiatan di kebun, asisten tanaman memberikan instruksi dan petunjuk pelaksanaan kegiatan kepada mandor kepala dan mandor, mengawasi kinerja mandor besar dan mandor, melaksanakan pembayaran gaji karyawan pada tanggal 5 dan 26 setiap bulan serta menyusun anggaran kegiatan kebun. Asisten tanaman juga menganalisis seluruh data kebun kemudian menyusun dan melaporkannya kepada manajer dalam bentuk RKAP afdeling.

Pendamping mandor besar. Mandor besar mengumpulkan hasil pekerjaan yang telah dilaksanakan hari tersebut dan mengevaluasi kegiatan yang telah dilaksanakan bersama asisten tanaman. Sebagai pendamping mandor besar, penulis bertugas membantu asisten tanaman untuk mengawasi dan member pengarahan pelaksanaan pekerjaan lapangan kepada mandor lapangan. Pada saat sebagai pendamping mandor besar, penulis melakukan pengontrolan kegiatan sulam kopi, kesrik mulching, membuat bulan-bulan, penyiangan kimia di TM, anjir tanaman kopi, membuat gandungan dan pemupukan.

Pendamping mandor. Mandor bertugas melaporkan pekerjaan di hari yang bersangkutan kepada juru tulis afdeling dan menerima pengarahan dari mandor besar dan asisten tanaman tentang lokasi dan jenis kegiatan yang akan dilaksanakan esok hari. Pada saat sebagai pendamping mandor, penulis berperan sebagai mandor bedengan, mandor pengajiran, mandor pembuatan lubang tanam, mandor pengendalian gulma manual, mandor pengendalian gulma secara kimia, mandor pembutan gandungan, mandor pemeliharaan naungan sementara, mandor persiapan pemupukan, mandor pemangkasan pemeliharaan, mandor pangkas bentuk.

\section{KESIMPULAN}

Kegiatan magang yang dilakukan telah meningkatkan pengetahuan mengenai teknik budidaya tanaman kopi. Penulis juga telah memperoleh pengalaman dan keterampilan kerja mulai dari karyawan harian lepas (KHL), mandor dan asisten tanaman dalam pengelolaan kopi secara teknis maupun manajerial khususnya aspek pemangkasan.

Tanaman kopi menghasilkan yang terdapat di Kebun Blawan sebagian besar $75 \%$ berumur lebih dari 20 tahun. Kondisi tanaman di Blok Kalirejo 1989 pada umumnya tinggi tanaman lebih dari $160 \mathrm{~cm}$ karena banyak cabang yang terlewat tidak dipangkas. Tinggi tanaman yang lebih dari 160 cm memiliki banyak cabang-cabang B3 dan B4 yaitu cabang-cabang tua yang mempunyai jumlah dompolan sedikit. Pemangkasan pemeliharaan/pemangkasan produksi terdiri atas pangkas lepas panen, pangkas seleksi atau wiwil selektif dan wiwil kasar. Cabang-cabang yang termasuk cabang produktif yaitu cabang B1, B2, dan B3. Jumlah cabang-cabang B3 tanaman kopi di Kebun Blawan jumlahnya sangat banyak. Cabang-cabang tanaman kopi yang tua di Kebun Blawan banyak tidak dipangkas. Cabang-cabang yang dipangkas saat ini sangat mempengaruhi jumlah cabang dan produksi untuk tahun selanjutnya.

\section{DAFTAR PUSTAKA}

Anggara, A., Marini, S. 2011. Kopi Si Hitam Menguntungkan Budi Daya dan Pemasaran. Jogyakarta (ID) : Cahaya Atma Pustaka.

[Ditjenbun] Direktorat Jenderal Perkebunan. 2013. Statistik Perkebunan Indonesia (Kopi) 2008 - 2012. Direktorat Jenderal Perkebunan, Departemen Pertanian. Jakarta (ID) : Deptan Press.

Kusmiati, A., Windiarti, R. 2011 Analisis wilayah komoditas kopi di Indonesia.J. J-Sep 5 (2) : 47-58

Panggabean, E. 2011. Buku Pintar Kopi. Jakarta (ID): Agromedia Pustak.

Prastowo, B., Karmawati, E., Rubijo, Siswanto, Indrawanto, C., Munarso, S. 2010. Budidaya dan Pasca Panen Kopi. Bogor (ID): Pusat Penelitian Perkebunan. 
[PTPN XII] PT Perkebunan Nusantara XII. 2012. Vademicum Kopi Arabika Periode 20112016. Surabaya (ID) : PTPN XII.

Rahardjo, P. 2012. Panduan Budidaya dan Pengolahan Kopi Arabika dan Robusta. Jakarta (ID): Penebar Swadaya.

Tampubolon, M. 2002. Pengelolaan Tanaman Kakao (Theobroma cacao L) dengan
Aspek Pemangkasan di Kebun Ngobo PTP Nusantara IX, Semarang Jawa Tengah [skripsi]. Bogor (ID) : Institut Pertanian Bogor.

Tim Karya Tani Mandiri. 2010. Pedoman Budi Daya Tanaman Kopi. Bandung (ID) : Nuansa Aulia. 